\title{
Probabilistic assessment of load-bearing capacity of deep beams designed by strut-and-tie method
}

\author{
Lidia Buda-Ożóg ${ }^{1, *}$ \\ ${ }^{1}$ Rzeszow University of Technology, 2 Poznańska, Rzeszów 35-084, Poland
}

\begin{abstract}
This paper presents probabilistic assessment of load-bearing capacity and reliability for different STM of deep beams. Six deep beams having different reinforcement arrangement obtained on the basis of STM but the same overall geometry and loading pattern were analysed. The used strut-and- tie models for D-regions of analysed elements have been verified and optimised by different researchers. In order to assess load-bearing capacity of these elements probabilistically, stochastic modelling was performed. In the presented probabilistic analysis of deep beams designed, the ATENA software, the SARA software and the CAST (computer-aided strut-and-tie) design tool were used. The reliability analysis shown that STM optimization should be a multi-criteria issue so that the obtained models were characterized by optimal stiffness with the assumed volume or weight and maximum reliability.
\end{abstract}

\section{Introduction}

The use of ST models for the design of reinforced concrete structures has a very long history and is practically inseparable from the history of reinforced concrete structures. The strut-and-tie model method is especially used in the design of D-regions where the Bernoulli hypothesis does not apply. An STM idealizes a complex force flow in the structures as a collection of compression members (struts), tension members (ties), and the intersection of such members (nodes). However, strut-and-tie modelling techniques have been extensively investigated since a comprehensive work was reported by Schlaich et al. [1], the standard recommendations and the literature do not provide rules allowing to unambiguously determine the shape and direction of elements in the ST method. Many different types of techniques and algorithms have been proposed by dozens of researchers and the selection of the optimal model is the subject of many scientific works published in recent years. In these works, different criteria for optimization of ST models are used, usually with omitting the reliability assessment of the obtained model. Design of safe structures should be the overriding objective, since the reliability of the structure is closely related to the ways of treating uncertainty and making decisions in the initial design phase.

In this paper, six deep beams having different reinforcement arrangement obtained on the basis of STM but the same overall geometry and loading pattern were analysed. In order to assess load-bearing capacity of these elements probabilistically, stochastic modelling was performed. In the paper, the method of randomization of variables during the Monte Carlo simulation was applied. The Latin Hypercube Sampling
(LHS) method was selected, in order to reduce the number of simulations to an acceptable level.

\section{ST models of deep beams}

The analysed deep beam with a rectangular opening is shown in Fig 1 .

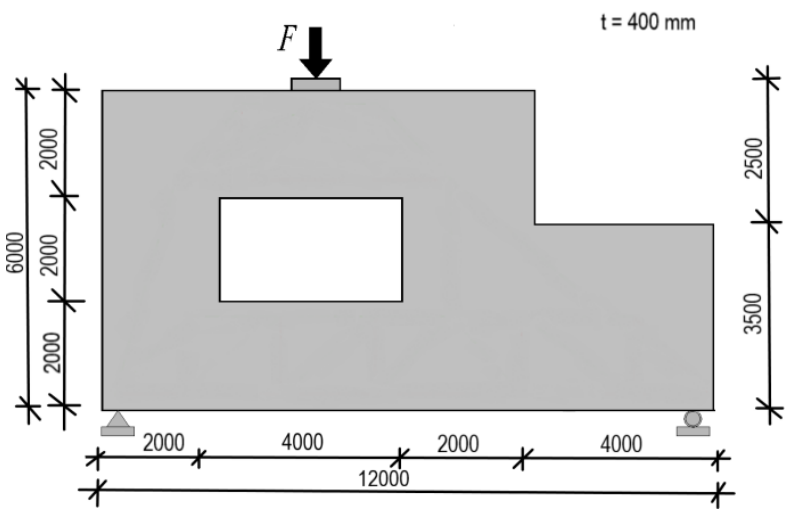

Fig. 1. Geometry and dimensions of analysed deep beam

This element was utilized by Novak and Sprenger [2] as a strong example for the application of strut-and-tie modelling of reinforced concrete structures. Deep beam as a whole is considered a D-region due to geometric and force discontinuity. In the analysed deep beam, the reinforcement was formed on the basis of six ST models. The strut-and-tie model - T1 is shown in Fig. 2. It was proposed by Novak and Sprenger [2]. It behaves as a socalled beam-on-beam, that is, an upper span is supported by a lower span.

After the Novak model, Reineck [3] proposed and investigated several different strut-and-tie models. One 
of the models analysed by Reineck was a model obtained through a frame analysis in which the upper beam is symmetrically supported and the lower beam- Fig.3. This is the second model analysed in this paper, marked as $\mathrm{T} 2$.

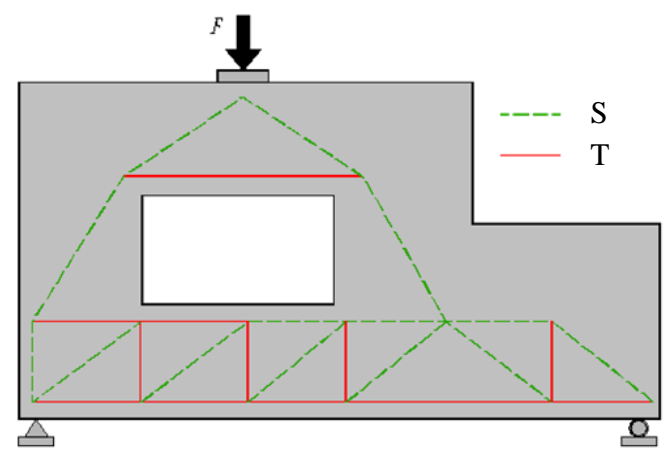

Fig. 2. STM of deep beam - T1, proposed by Novak and Sprenger [2]

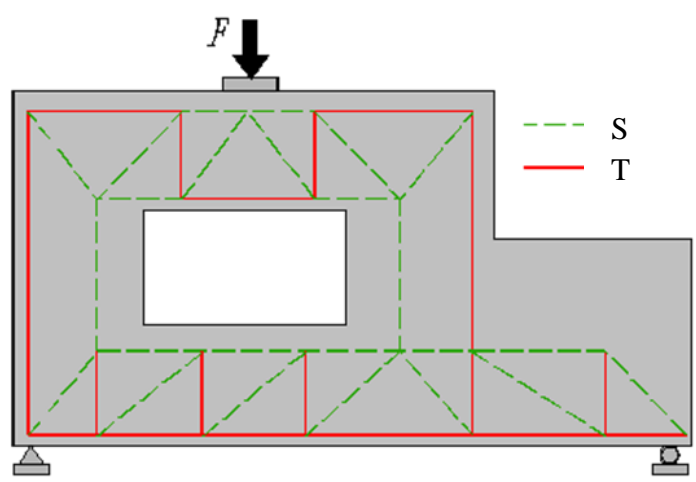

Fig. 3. STM of deep beam - T2, proposed by Reineck [3]

In the next years, this classical example of D-region has attracted widespread attention from other researchers. Ley et al. [4] developed some other STMs and conducted a series of experiments to verify the application of strut-and-tie modelling. Two of the STM analysed by Ley et al. are shown in Fig. 4 i 5 . They are the third STM of the analysed deep beam marked as T3 and the fourth STM built using the load path - marked as T4.

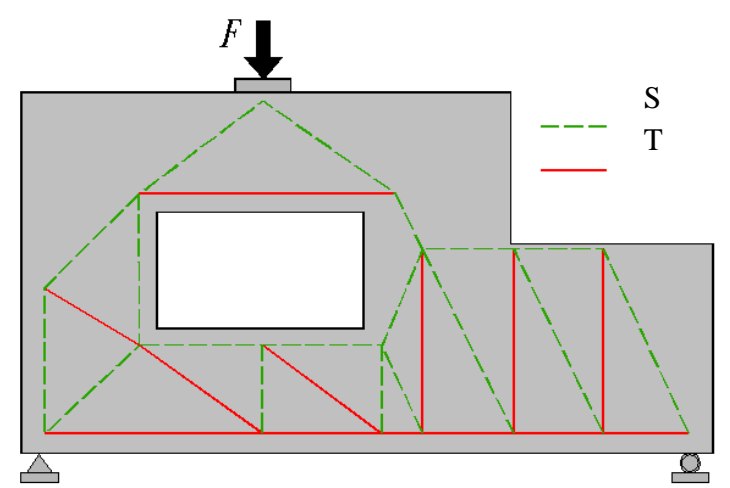

Fig. 4. STM of deep beam - T3, proposed by Ley et al [4]

The next STM of deep beam -T5 was proposed by Herenza et al. [5]. In this model the Full
Homogenization $(\mathrm{FH})$ optimization method to determine the shape of strut-and-tie model was used - Fig. 6.

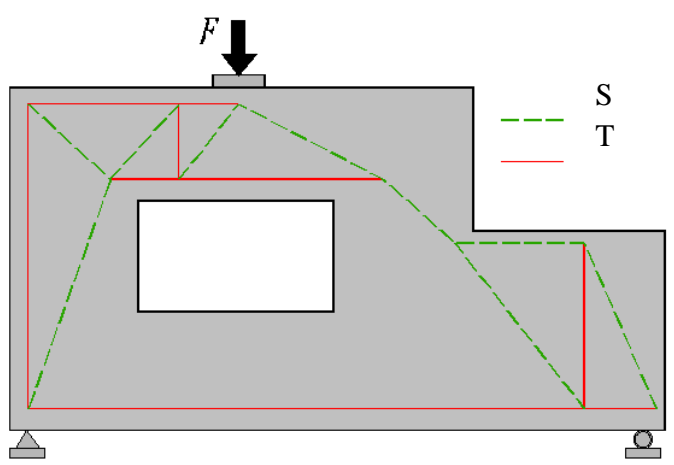

Fig. 5. STM built using the load - T4, proposed by Ley et al [4]

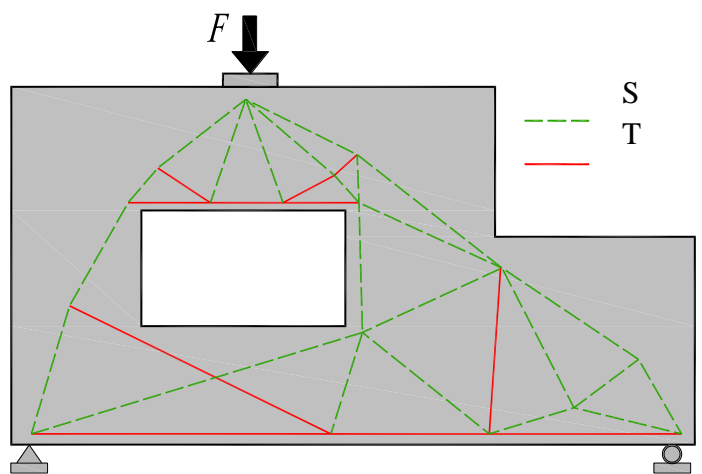

Fig. 6. STM on the basic of full homogenization (FH) optimization method - T5, proposed by Herenza et al. [5]

The last of the analysed STM of the deep beam- T6 was the model proposed by Zhong et al. [6]. The Ground Structure Method (GSM) was used to generate this strut-and-tie model, shown in Fig. 7.

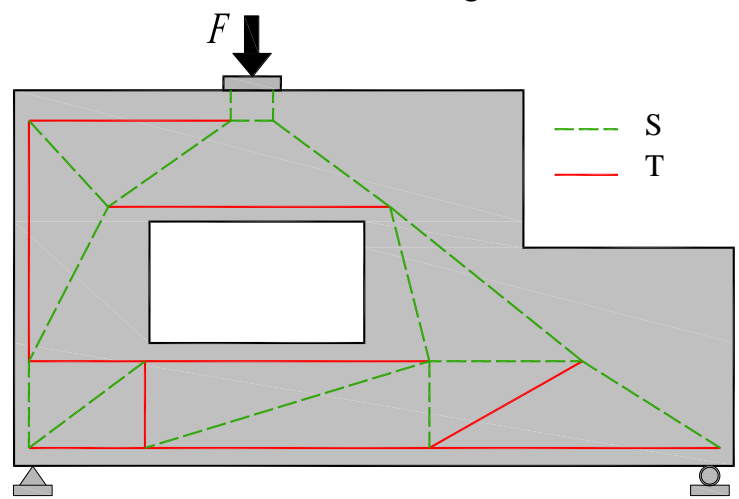

Fig. 7. STM on the basic of ground structure method (GSM) T6 proposed Zhong et al. [6]

The reinforcement in the analysed deep beams were designed by the computer aided strut-and-tie (CAST) design tool [7]. The CAST is a graphical design tool that allows the user to customize D-regions, draw an internal truss, check the nodes, select the width of strut members and tie reinforcement. 


\section{Numerical model of the deep beams}

In the next steps, numerical simulations of the analysed six deep beams by means of the nonlinear mechanics software ATENA [13] were performed. A numerical model was considered in two-dimensional stress state. To solve static problems of reinforced concrete deep beams, calculation procedure based on Newton Raphson iterative method was applied. Newton-Raphson method keeps the load increment unchanged and iterates displacements until equilibrium is satisfied within the given tolerance. To model the concrete the material model SBETA proposed by ATENA (Advanced Tool for Engineering Nonlinear Analysis) was used. The material model SBETA includes the following effects of concrete behaviour:

-non-linear behaviour in compression including hardening and softening;

-fracture of concrete in tension based on the nonlinear fracture mechanics;

-biaxial strength failure criterion;

-reduction of compressive strength after cracking;

-tension stiffening effect;

-reduction of the shear stiffness after cracking;

-two crack models: fixed crack direction and rotated crack direction.

The basic constitutive characteristics of concrete are shown in Table 1.

Table 1. The basic material properties of material model SBETA

\begin{tabular}{|c|c|}
\hline Material Properties & Value \\
\hline $\mathrm{E}_{\mathrm{c}}-$ Elastic modulus $\left[\mathrm{N} / \mathrm{mm}^{2}\right]$ & 31140 \\
\hline $\mathrm{f}_{\mathrm{t}}-$ Tensile strength $\left[\mathrm{N} / \mathrm{mm}^{2}\right]$ & 2.42 \\
\hline $\mathrm{G}_{\mathrm{f}}-$ Fracture energy $[\mathrm{N} / \mathrm{m}]$ & 60.48 \\
\hline $\mathrm{f}_{\mathrm{c}}-$ Compressive Strength $\left[\mathrm{N} / \mathrm{mm}^{2}\right]$ & 27.20 \\
\hline $\begin{array}{c}\varepsilon \text { - Compressive Strain at compressive } \\
\text { strength in the uniaxial compressive test }\end{array}$ & 0.00175 \\
\hline$v$ - Poisson's ratio & 0.20 \\
\hline
\end{tabular}

For modelling the main reinforcement, the material model "reinforcement", proposed by ATENA was used. The model of elastic-plastic material, with characteristics corresponding to steel RB500W, was used. The numerical model deep beams -T4 is shown in Fig. 8 .

Fig.9 shows the dependence between load and displacement of the point situated at the centre of span obtained for all tested deep beams.

To validate the numerical model, experimental results of the deep beam -T4 made in scale 1:10.5 presented in the literature [5] are used.

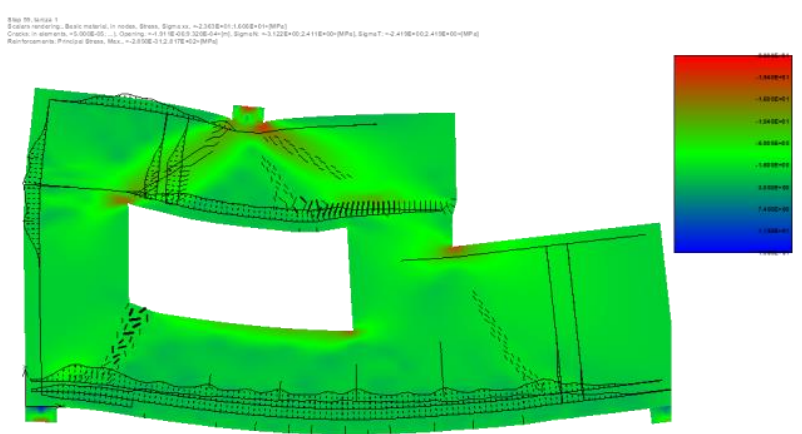

Fig. 8. Stresses, deformation and cracks in numerical model of deep beam $\mathrm{T} 4$

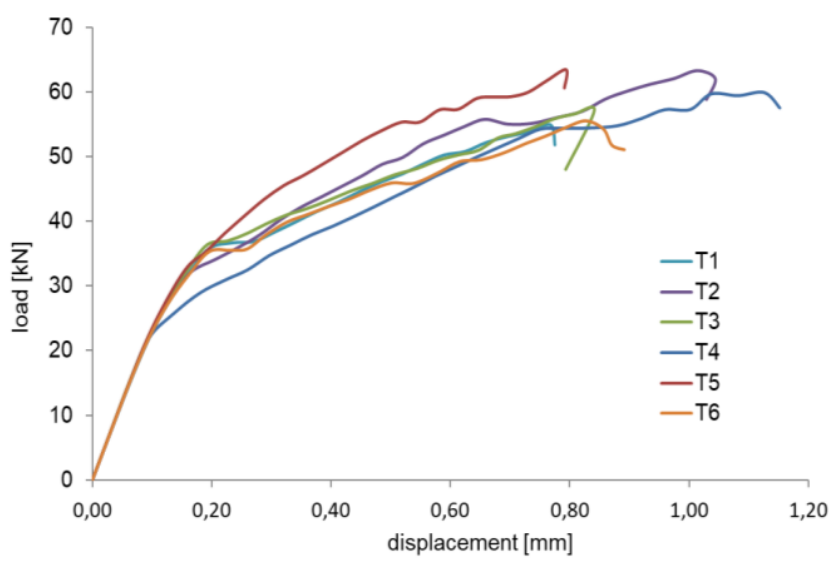

Fig. 9. The dependence between load and displacement for tested deep beams

In the Table 2 comparison of the load-bearing capacity for the T4 deep beam obtained by Ley et al. during experimental studies and numerical simulations made with ATENA program were presented.

Table 2. Experimental and numerical results for the deep beam - T4.

\begin{tabular}{|c|c|}
\hline & $\begin{array}{c}\text { Failure load } \\
{[\mathbf{k N}]}\end{array}$ \\
\hline Experimental research & 55.2 \\
\hline Numerical simulations & 59.9 \\
\hline
\end{tabular}

The observed differences are caused by incomplete information about the materials used in experimental studies and the differences in the geometry of numerical and experimental deep beams. The numerical models were made in scale 1:10.

\section{Stochastic modelling}

Behaviour of deep beams under load was analysed in detail by a stochastic modelling. The objective was to find out impacts of type of STM and some input data onto the bearing capacity of deep beam. For timeintensive calculations, the small-sample simulation techniques based on stratified sampling of Monte Carlo 
type represent a rational compromise between feasibility and accuracy. Therefore in presented simulations, Latin hypercube sampling (LHS) was selected as a key fundamental technique. The basic feature of LHS is that the probability distribution functions for all random variables are divided into $\mathrm{N}_{\text {Sim }}$ equivalent intervals $\left(\mathrm{N}_{\text {Sim }}\right.$ is a number of simulations); the values from the intervals are then used in the simulation process (random selection, middle of interval or mean value). This means that the range of probability distribution function of each random variable is divided into intervals of equal probability. The samples are chosen directly from the distribution function based on an inverse transformation of distribution function. The representative parameters of variables are selected randomly, being based on random permutations of integers $1,2, \ldots, \mathrm{j}, \mathrm{N}_{\text {Sim. }}$. Every interval of each variable must be used only once during the simulation - Fig.10. Being based on this precondition, a table of random permutations can be used conveniently, each row of such a table belongs to a specific simulation and the column corresponds to one of the input random variables [8].

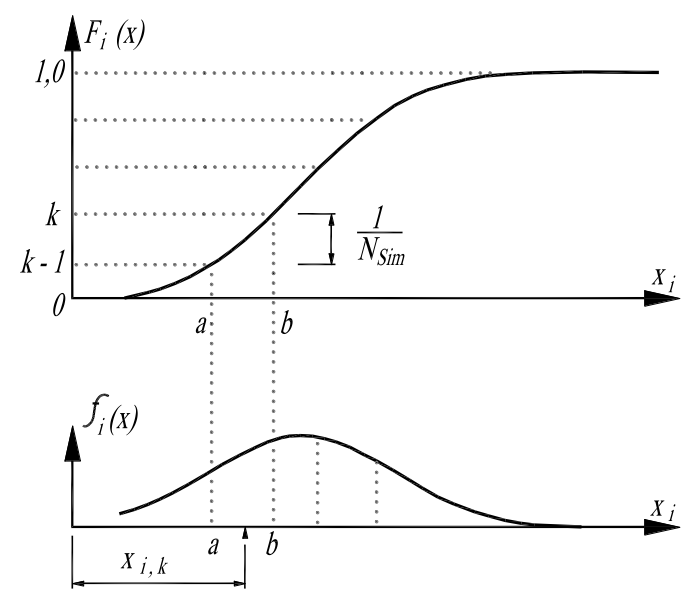

Fig. 10. Illustration of LHS - samples as the probabilistic means of intervals

The mean of each interval should be chosen as (1):

$$
x_{i, k}=\frac{\int_{y_{i, k-1}}^{y_{i, k}} x f_{i}(x) d x}{\int_{y_{i, k-1}}^{y_{i, k}} f_{i}(x) d x}=N_{S i m} \cdot \int_{y_{i, k-1}}^{y_{i, k}} x \cdot f_{i}(x) d x
$$

where $f_{i}$ is the probability density function of variable $X_{i}$ and the integration limits are (2):

$$
y_{i, k}=F_{i}^{-1}\left(\frac{k}{N_{S i m}}\right)
$$

The estimated mean value is achieved accurately and the variance of the sample set is much closer to the target one [14].

In the analysis the random character of input data concrete and steel was assumed. For each the deep beams 50 simulation were performed with modified statistic parameters. Statistic parameters were described using the recommendations specified in JCSS [9], ISO [10] and [11]. The input values should be properly described, e.g. with a mean value, coefficient of variation, or type of distribution. The distribution and coefficient of variation - COV for the input variables of concrete and steel are shown in Table 3. The Fig.11 shows exemplary histogram for 50 randomized parameters generated by using the LHS technique.

Table 3. Material properties in the stochastic modelling.

\begin{tabular}{|c|c|l|}
\hline Input & COV & Distribution \\
\hline $\mathrm{E}_{\mathrm{c}}$ & 0.15 & Lognormal \\
\hline $\mathrm{f}_{\mathrm{t}}$ & 0.18 & Lognormal \\
\hline $\mathrm{G}_{\mathrm{f}}$ & 0.20 & Lognormal \\
\hline $\mathrm{f}_{\mathrm{c}}$ & 0.13 & Lognormal \\
\hline $\mathrm{f}_{\mathrm{y}}$ & 0.05 & Lognormal \\
\hline
\end{tabular}

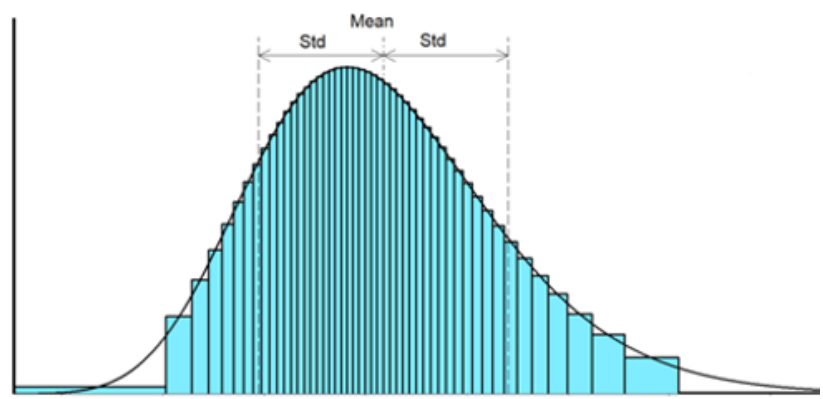

Fig. 11. Histogram of input value $\mathrm{G}_{\mathrm{f}}$ obtained by LHS technique for 50 samples.

In analysis the correlation between parameters of concrete were taken. Table 4 shows the correlation matrix used for the concrete in the stochastic modelling. Expected values of the correlation matrix are shown in the right part of matrix. Values obtained by simulated annealing for one of deep beams shown in the left part of matrix.

Table 4. Correlation matrix of concrete.

\begin{tabular}{|c|l|c|c|l|}
\hline Input & $\mathbf{E}_{\mathbf{c}}$ & $\mathbf{f}_{\mathbf{t}}$ & $\mathbf{G}_{\mathbf{f}}$ & $\mathbf{f}_{\mathbf{c}}$ \\
\hline $\mathbf{E}_{\mathbf{c}}$ & 1 & 0.9 & 0.5 & -0.7 \\
\hline $\mathbf{f}_{\mathbf{t}}$ & 0.868 & 1 & 0.9 & -0.8 \\
\hline $\mathbf{G}_{\mathbf{f}}$ & 0.518 & 0.866 & 1 & -0.6 \\
\hline $\mathbf{f}_{\mathbf{c}}$ & -0.703 & -0.795 & -0.603 & 1 \\
\hline
\end{tabular}




\section{Results of analysis}

The stochastic modelling was carried out using SARA [12] software application. Example results of the analysis for one of the six deep beams are shown in Fig.12. In the diagram dependence of load- displacement obtained for all tasks generated for the deep beam T2 are shown.

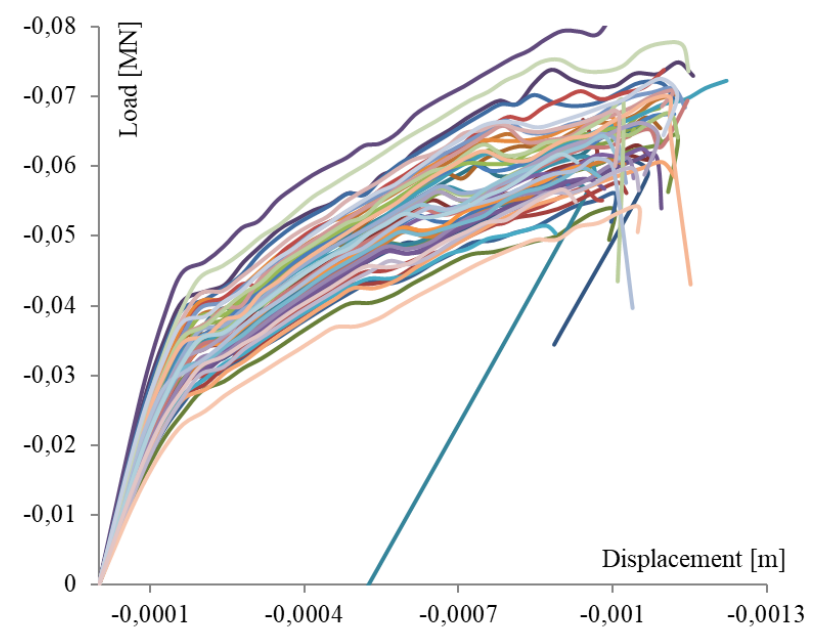

Fig. 12. The dependence between load and displacement for all tasks generated for the deep beam T2

For each of the deep beams the result of the stochastic simulations were: estimations of the mean value, variance, coefficient of skewness, kurtosis and empirical cumulative probability density function estimated by empirical histogram structural response. This basic statistical assessment are visualized through the histograms. The histograms with estimate ultimate load for each deep beam are shown in Fig 13- 18.

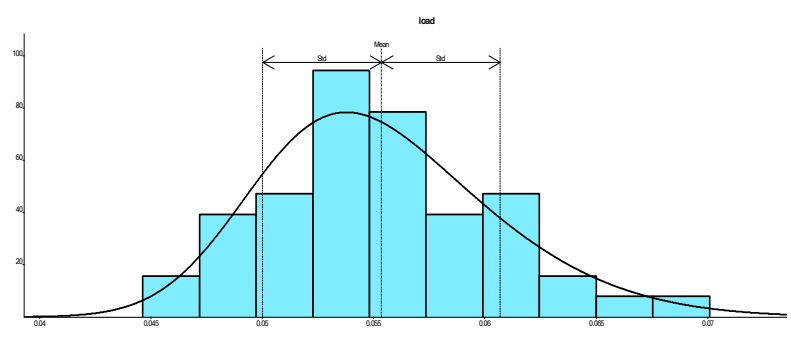

Fig. 13. Histogram of ultimate load for the deep beam T1

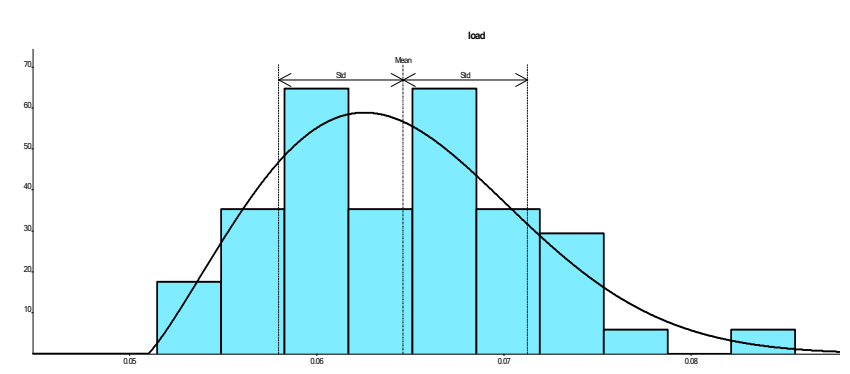

Fig. 14. Histogram of ultimate load for the deep beam $T 2$

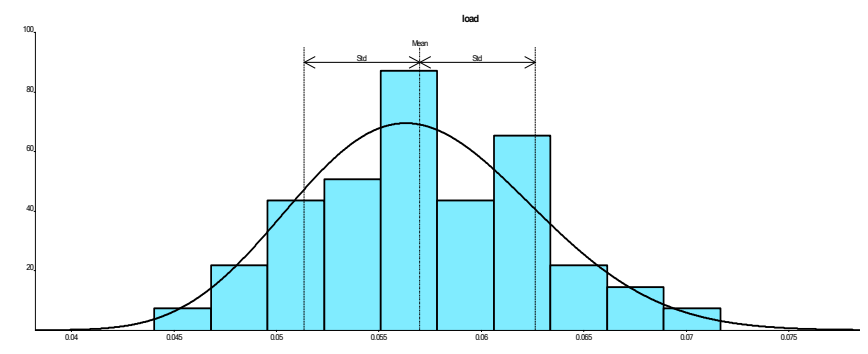

Fig. 15. Histogram of ultimate load for the deep beam T3

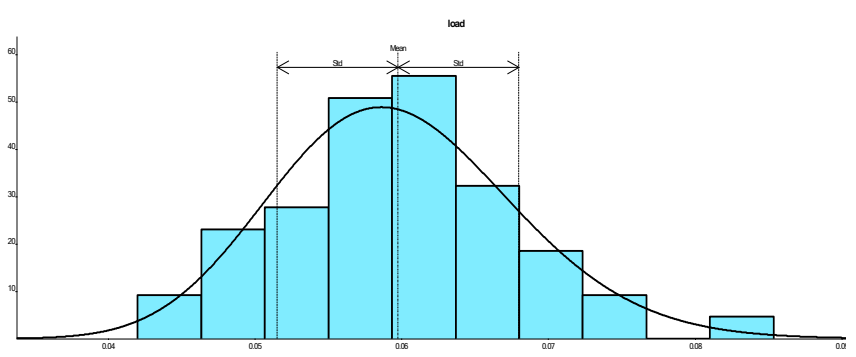

Fig. 16. Histogram of ultimate load for the deep beam T4

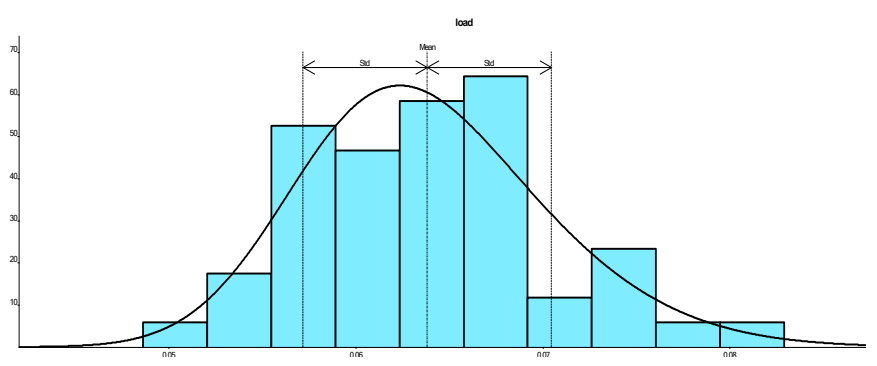

Fig. 17. Histogram of ultimate load for the deep beam T5

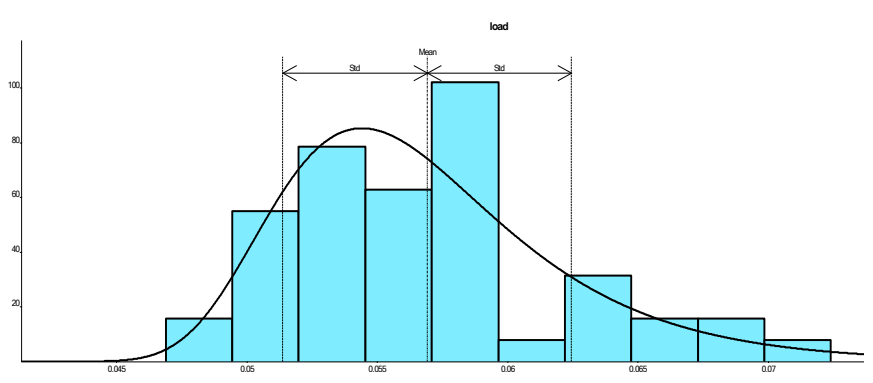

Fig. 18. Histogram of ultimate load for the deep beam T6

The mean value of the ultimate load- $\mathrm{P}$, confidence level, standard deviation, COV, coefficient of skewness, kurtosis, the upper value - $\mathrm{P}_{\text {sup }}$, the lower value $-\mathrm{P}_{\text {inf }}$ and reliability index $-\beta_{c}$ for load bearing capacity are compared in tables 5 and 6 . Than $\mathrm{P}_{\text {inf }}$ is the $5 \%$ fractile and $\mathrm{P}_{\text {sup }}$ is the $95 \%$ fractile of the statistical distribution for $P$. 
Table 5. Mean value, standard deviation, COV and reliability index for load bearing capacity

\begin{tabular}{|c|c|c|c|c|}
\hline Element & $\begin{array}{c}\text { P- mean } \\
\text { value } \\
{[\mathbf{k N}]}\end{array}$ & $\begin{array}{c}\text { Standard } \\
\text { deviation } \\
{[\mathbf{k N}]}\end{array}$ & $\mathbf{C O V}$ & $\boldsymbol{\beta c}$ \\
\hline $\mathrm{T} 1$ & 55.3 & 5.33 & 0.096 & 10.37 \\
\hline $\mathrm{T} 2$ & 64.6 & 6.65 & 0.103 & 9.72 \\
\hline $\mathrm{T} 3$ & 57.0 & 5.63 & 0.099 & 10.11 \\
\hline $\mathrm{T} 4$ & 59.7 & 8.24 & 0.138 & 7.25 \\
\hline $\mathrm{T} 5$ & 63.8 & 6.65 & 0.104 & 9.60 \\
\hline $\mathrm{T} 6$ & 56.9 & 5.54 & 0.097 & 10.27 \\
\hline
\end{tabular}

Table 6. Skewness and kurtosis, upper and lower value of load bearing capacity

\begin{tabular}{|c|c|c|c|c|}
\hline Element & Skewness & Kurtosis & $\begin{array}{c}\mathbf{P}_{\text {inf }}[\mathbf{k N ]} \\
\text { T1 }\end{array}$ & $\begin{array}{c}\mathbf{P}_{\text {sup }} \\
{[\mathbf{k N}]}\end{array}$ \\
\hline $\mathrm{T} 2$ & 0.510 & 0.214 & 47.4 & 64.9 \\
\hline $\mathrm{T} 3$ & 0.208 & -0.119 & 48.1 & 66.6 \\
\hline $\mathrm{T} 4$ & 0.403 & 0.623 & 46.8 & 73.9 \\
\hline $\mathrm{T} 5$ & 0.394 & 0.252 & 53.7 & 75.5 \\
\hline T6 & 1.140 & 2.400 & 49.7 & 67.2 \\
\hline
\end{tabular}

An important task in the structural reliability analysis is to determine the significance of random variables how they influence a response function of a specific problem. A sensitivity analysis can answer the question „what variables are the most important ?". In probabilistic assessment of the deep beams the sensitivity analysis based on the comparison of partial coefficient of variation of the structural response variable with variation coefficient of basic random variables were performed. The rank-order statistical correlation is expressed by the Spearman correlation coefficient and nonparametric rank-order correlation coefficients are calculated between all random input variables and response variables by formula (3):

$$
r_{s}=1-\frac{6 \sum_{i=1}^{N_{S i m}} d_{i}^{2}}{N_{S i m}\left(N_{S i m}-1\right)\left(N_{S i m}+1\right)}
$$

where $d_{i}$ is the difference of the order of the components in sequenced statistical files and $n$ is the range of the statistical file

The sensitivity analysis between variables and ultimate load, for the deep beams are compared in Table 7.
Table 7. Correlation coefficients between variables and ultimate load

\begin{tabular}{|c|c|c|c|c|c|c|}
\hline & $\mathrm{T} 1$ & $\mathrm{~T} 2$ & $\mathrm{~T} 3$ & $\mathrm{~T} 4$ & $\mathrm{~T} 5$ & $\mathrm{~T} 6$ \\
\hline $\mathrm{f}_{\mathrm{c}}$ & 0.96 & 0.94 & 0.96 & 0.87 & 0.92 & 0.92 \\
\hline $\mathrm{f}_{\mathrm{t}}$ & 0.88 & 0.89 & 0.88 & 0.96 & 0.92 & 0.85 \\
\hline $\mathrm{E}$ & 0.77 & 0.74 & 0.80 & 0.82 & 0.81 & 0.74 \\
\hline $\mathrm{G}_{\mathrm{f}}$ & 0.71 & 0.71 & 0.66 & 0.79 & 0.70 & 0.64 \\
\hline $\mathrm{f}_{\mathrm{y}}$ & 0.05 & 0.05 & 0.04 & 0.00 & 0.03 & 0.04 \\
\hline
\end{tabular}

In most cases, the concrete properties had biggest impact on the structure response. A high positive correlation coefficient, more than 0.9 , indicates that the response or limit state function is very sensitive to that particular variable. For the compression strength of concrete, in the case of the deep beam T4, correlation coefficient is smaller than in other analysed deep beams.

After statistical analyses the reliability analyses were carried out. The limit state function $-Z$ (margin of safety) was formulated (4).

$$
Z=R-E
$$

This function is a difference between resistance $-\mathrm{R}$ and load effect - E.

According to the original assumptions, the load effect applied to the considered deep beams was $25 \mathrm{kN}$. For this load effect, probabilistic description by means of normal distribution with COV 0.15 is used.

In this case, reliability analysis methods employing Cornell's reliability index $-\beta c$ and corresponding failure probability (Cornell - pf) were carried out. Estimation of Cornell's reliability index requires the estimation of basic statistical characteristics of safety margin. The Cornel reliability index expresses the formula (5):

$$
\beta_{c}=\frac{\mu_{z}}{\sigma_{z}}
$$

where $\mu_{\mathrm{Z}}$ and $\sigma_{\mathrm{Z}}$ are the mean value and the standard deviation of the safety margin $\mathrm{Z}$.

The estimated reliability index and the adopted efficiency indexes for six deep beams are compared in table 8. Efficiency indexes were defined as the ratio between the load bearing capacity to the reinforcement mass and the ratio of the reliability index to the reinforcement mass. 
Table 8. Reliability index and efficiency indexes for deep beams

\begin{tabular}{|c|c|c|c|c|}
\hline \multirow{2}{*}{ Element } & \multirow{2}{*}{$\begin{array}{c}\text { M - mass } \\
\text { of steel } \\
{[\mathbf{k g}]}\end{array}$} & $\boldsymbol{\beta} \mathbf{c}$ & \multicolumn{2}{|c|}{ Efficiency indexes } \\
\cline { 4 - 5 } & 1.37 & 4.63 & 40.4 & 3.38 \\
\hline $\mathrm{T} 1$ & 1.95 & 5.14 & 33.2 & 2.63 \\
\hline $\mathrm{T} 2$ & 1.58 & 4.72 & 36.1 & 2.99 \\
\hline $\mathrm{T} 3$ & 1.51 & 3.78 & 39.5 & 2.55 \\
\hline $\mathrm{T} 4$ & 1.65 & 5.12 & 38.7 & 3.10 \\
\hline $\mathrm{T} 5$ & 1.1 & 4.73 & 51.7 & 4.30 \\
\hline $\mathrm{T} 6$ & & &
\end{tabular}

The largest value of reliability index and the highest load bearing capacity for the deep beams T2 and T5 ware obtained. On the other hand, the T2 deep beam is the least economical as it has the largest reinforcement mass among all the deep beams being analysed. Analysing results presented in the table 8, it can be seen that in the case of the deep beam- T4 with reinforcement obtained on the basis of the load path, the reliability index doesn't meet the requirements for the RC 2 class and $\mathrm{T}=50$ years, defined in PN-EN-1990 $(\beta \geq 3.8)$.

The largest value of efficiency indexes, i.e. the ratio between load bearing capacity to the reinforcement mass and the ratio of the reliability index to the reinforcement mass were obtained for the deep beam T6.

\section{Conclusion}

This paper presents probabilistic assessment of loadbearing capacity and reliability for different STM of deep beams. In the presented probabilistic analysis of deep beams designed by strut-and-tie method, the ATENA software, the SARA software and the CAST (computer-aided strut-and-tie) design tool were used.

Summing up the results of the analysis, the following detailed conclusions can be formulated:

- structures designed on the basis of different ST models are characterized by different load bearing capacity and different mass of reinforcement. The mean value of load bearing capacity ranged from $55.3 \mathrm{kN}$ for the deep beam T1 to $64.6 \mathrm{kN}$ for the deep beam T2. The observed differences in the value of maximum output is around $15 \%$, and in each analyzed case load capacity requirement was met. Significant differences (around $80 \%$ ) were observed in the mass of reinforcement required to design the deep beams;

- the result of the stochastic simulations shows that the coefficients of variation are similar for most tested deep beams and these is $10 \%$. Only for the deep beam $\mathrm{T} 4$ the higher coefficient of variation $-14 \%$ is obtained;

- the strut-and-tie models are also characterized by different reliability structures. The similar value of reliability index for resistance were obtained for the deep beams T1, T3 and T6 and these are about 10 but for the deep beam T4 reliability index is only 7.25.

- the reliability analysis shows that in the case of the deep beam- T4 with reinforcement obtained on the basis of the load path, the reliability index doesn't meet the requirements for the RC 2 class and $\mathrm{T}=50$ years. In the other analysed cases the Cornel reliability index ranges from 4.63 to 5.14 and reliability requirements defined in PN-EN-1990 are met.

- the largest value of efficiency indexes i.e. the ratio between load bearing capacity to the reinforcement mass and the ratio of the reliability index to the reinforcement mass were obtained for the deep beam T6 with STM on the basic of the Ground Structure Method.

In conclusion, as ensuring safety of a structure should be the primary goal, STM optimization should be a multi-criteria issue so that the obtained models were characterized by optimal stiffness with the assumed volume or weight and maximum reliability.

\section{References}

1. Schlaich J, Schäfer K, Jennewein M. Toward a consistent design of structural concrete. PCI J 32 (3), 74-150 (1987)

2. Novak L. i Sprenger H., Example 4: deep beam with opening in examples for design of structrual concrete with strut-and- tie models, w ACI Fall Convention, 2002.

3. K. Reineck, Modeling Structural Concrete with Strut-and-Tie Models, Summarizing Discussion of the Examples, Appendix A of ACI 318-02, p. 225-242, 2002.

4. M. Ley, K. Riding, Experimental Verification of Strut-and-Tie Model Design Method, ACI Structural Journal, 104, 749-755 (2007)

5. J. Herranz, S. Gutiérrez, R. Riddell, Optimal Strut-and-Tie Models Using Full Homogenization, Optimization Method, ACI Structural Journal, 605-613 (2012)

6. J. Zhong, L. Wang, P. Deng, M. Zhou, A new evaluation procedure for the strut-and-tie models of the disturbed regions of reinforced concrete structures, Engineering Structures 148, 660-672 (2017).

7. DA. Kuchma, TN. Tjhin, CAST (Computer Aided Strut-and-Tie) design tool. In: Structures congress, 1-7 (2001)

8. D. Novák, Small-sample simulation for uncertainties modelling in engineering: Theory, software and applications. Presented at the 3rd Weimar Optimization and Stochastic Days 2006.https://www.dynardo.de/.../WOST_3_Sma 11SampleSimulation_En

9. ISO 2394 General principles on reliability for structures, ISO (2010)

10. JCSS: Probabilistic model code. JCSS working material [online], http://www.jcss.ethz.ch/, (2012). 
11. Sz. Woliński, Niezawodność konstrukcji budowlanych. Rozdział 4.11, w: Praca zbiorowa, Budownictwo ogólne. T.3, Arkady, Warszawa 2008, s. 376-419 (in Polish)

12. SARA Program Documentation, Praga, 2015

13. ATENA Program Documentation, Praga 2014

14. FREET Program Documentation, Brno, 2006 